HEALTH PSYCHOLOGY REPORT · VOLUME 8(2), 2020 ORIGINAL ARTICLE
Iliana Goula

$1 \cdot \mathrm{A}, \mathrm{B}, \mathrm{C}$

Victoria Alikari (D)

$2 \cdot \mathrm{D}, \mathrm{E}, \mathrm{F}$

Georgios Charalampous

$3,4 \cdot \mathrm{A}, \mathrm{B}, \mathrm{D}$

Foteini Tzavella

$5 \cdot \mathrm{A}, \mathrm{B}, \mathrm{F}$
Sofia Zyga

$5 \cdot \mathrm{D}, \mathrm{E}, \mathrm{F}$

Maria Tsironi

$5 \cdot \mathrm{C}, \mathrm{D}, \mathrm{E}$

Paraskevi Theofilou

$6,7 \cdot A, C, F$

\title{
Social support and quality of life in Greek women with breast cancer during chemotherapy and two years later
}

\begin{abstract}
BACKGROUND
Social support in women with breast cancer is associated with quality of life (QoL) and it appears to be vital for treating breast cancer and adaptation to disease. Social support seems to decrease quantitatively and over time while significant improvement in the patients' long-term emotional and physical function is observed. Therefore, the aim of this study was to investigate the differences in levels of social support and QoL in two independent groups of patients: women with breast cancer (i) during chemotherapy and (ii) two years after the chemotherapy.
\end{abstract}

\section{PARTICIPANTS AND PROCEDURE}

In this cross-sectional study 74 women with breast cancer "during chemotherapy" $(n=41)$ and "two years after chemotherapy" $(n=33)$ completed the Greek version of Multidimensional Scale of Perceived Social Support (MSPSS) and the Greek version of the Missoula-VITAS Quality of Life Index (MVQoLI-15) to measure social support and QoL respectively. All statistical analyses were performed with SPSS 25 with significance set at $p<.05$.

\section{RESULTS}

The group "two years after chemotherapy" reported better QoL than the "during chemotherapy" group. There was no difference in perceived social support between the two groups. The higher the patients' age, the lower the QoL for the "during chemotherapy" group and the higher the social support for the "two years after chemotherapy" group.

\section{CONCLUSIONS}

QoL improves over time, emphasizing the ability of women to manage difficult situations. Social support remains important in both periods.

KEY WORDS

psycho-oncology; quality of life; social support

ORGANIZATION - 1: Department of Psychology, University of Central Lancashire, United Kingdom · 2: Department of Nursing, University of West Attica, Athens, Greece · 3: Ippokrateio General Hospital of Athens, Greece ·

4: Frederick University, Nicosia, Cyprus · 5: Department of Nursing, University of Peloponnese, Tripoli, Greece ·

6: General Direction of Health Services, Ministry of Health, Athens, Greece · 7: Institution for Counseling

\& Psychological Studies, Athens, Greece

AUthors' CONTRibutions - A: Study design - B: Data collection - C: Statistical analysis - D: Data interpretation .

E: Manuscript preparation · F: Literature search · G: Funds collection

CORRESPONDIng AUthor - Victoria Alikari, Ph.D., Department of Nursing, University of West Attica, 28 Spiridonos Str., 12243 Egaleo, Athens, Greece, e-mail: vicalikari@gmail.com

to Cite this ARticle - Goula, I., Alikari, V., Charalambous, G., Tzavella, F., Zyga, S., Tsironi, M., \& Theofilou, P. (2020).

Social support and quality of life in Greek women with breast cancer during chemotherapy and two years later.

Health Psychology Report, 8(2), 97-106. https://doi.org/10.5114/hpr.2020.93757

RECEIVED 06.01.2020 • REVIEWED 20.02.2020 • ACCEPTED 20.02.2020 • PUBLISHED 17.03.2020 


\section{BACKGROUND}

The quality of life (QoL) for women with breast cancer appears to be exceptionally low since the treatments and the breast cancer as a disease itself affect the physical, psychological and social function in various ways. More specifically, according to the majority of the conducted studies, patients with breast cancer have very low QoL (Fradelos et al., 2017).

Studies focusing on adjuvant therapies have re-

Iliana Goula, Victoria Alikari, Georgios Charalampous, Foteini Tzavella, Sofia Zyga, Maria Tsironi, Paraskevi Theofilou ported negative effects on body image, psychosocial well-being, physical function (Turgay, Khorshid, \& Eser, 2008), social function and hence the QoL during adjuvant chemotherapy (Rivera \& Cianfrocca, 2015). It has been found that chemotherapy is associated with nausea, vomiting, hair loss, cognitive dysfunction, fatigue and sexual dysfunction (Kurca \& Kutlutürkan, 2018). After chemotherapy, patients report reduced activity, fatigue, more need for sleep and more sexual dysfunction than before chemotherapy (Turgay et al., 2008). In addition, patients receiving chemotherapy on a clinical day may have more difficulty managing the side effects of chemotherapy at home (Turgay et al., 2008).

However, it has been claimed that patients with breast cancer have the ability to adapt to the difficulties of their situation (Gibek \& Sacha, 2019). Engel et al. (2003) found that there was a significant improvement in the patients' long-term emotional and social function. Fatigue, nausea, vomiting, future health concerns and pain decreased, while appetite and overall QoL scores increased within the next three years after the chemotherapy. Significant long-term improvements have been reported in postoperative symptoms and side effects, future prospects and patient communication with doctors especially in women under 50 (Bloom, Stewart, Chang, \& Banks, 2004). On the other hand, Burgess et al. (2005) reported in their five-year observation study that women with early-stage breast cancer continue to suffer from depression or anxiety one year after diagnosis and some of them for more than five years. Finally, Engel et al. (2003) reported that most changes in QoL occur between the first and second year after surgery to treat breast cancer.

There is a plethora of conducted studies so far that have attempted to investigate the factors that can affect the QoL for patients with breast cancer (Sharma \& Purkayasha, 2017; Lavdaniti et al., 2019). Indeed, studies have shown that younger women are affected more in their long-term social, economic, psychological, and mental health well-being than older women (Engel et al., 2003; Sammarco, 2009). Furthermore, the younger and the unmarried women were positively associated with poorer mental well-being and more severe depressive symptoms (Martínez et al., 2017). Additionally, Rustøen, and Schjølberg (2000) reported that the work situation is the most important factor that affects the well-being of the older age group. Em- ployed women reported better QoL than unemployed or retired women. Women with employment and a high level of education have better QoL than the opposites or retired (Timperi et al., 2013).

The concept of social support in women with breast cancer is associated with QoL and it seems to be vital for treating breast cancer and adaptation to disease-related anxiety (Salonen et al., 2013). The main sources of emotional support for breast cancer patients are usually family members, health professionals and volunteer survivors of breast cancer. Emotional support for two months and emotional and informative support for five months after breast cancer diagnosis are positively correlated with good QoL and patients' self-esteem (Arora, Rutten, Gustafson, Moser, \& Hawkins, 2007). Women who underwent chemotherapy received more emotional support while women who underwent a mastectomy received more physical support (Bloom, Stewart, Johnston, Banks, \& Fobair, 2001).

Breast cancer patients have a variety of support needs which remain after hospitalization and for prolonged periods of time to deal with the disease threat (Akechi et al., 2015). However, long-term studies with women diagnosed with breast cancer have shown that social support decreases quantitatively and over time (Arora et al., 2007). Women with breast cancer receive informative support three-five months after surgery by health professionals, emotional support from family and friends and support in decision-making by health professionals and family members (Arora et al., 2007). Age has been found to be particularly important in terms of support needs and the quantity and type of social support, while younger women reported greater needs for emotional support from health professionals (Wyatt, Beckrow, Gardiner, \& Pathak, 2008).

The purpose of this study was to examine the differences in levels of social support and QoL in two independent groups of patients: (i) women with breast cancer during chemotherapy and (ii) women with breast cancer two years after the chemotherapy as well as the relationship between social support and quality of life in each group. It was hypothesized that social support decreases over time while the quality of life increases over time. There is expected to be found a strong relationship between social support and quality of life. The effect of demographic variables in these two variables was, also, investigated. This is the first study exploring social support and QoL in breast cancer patients under chemotherapy and two years later either in Greece or internationally.

\section{PARTICIPANTS AND PROCEDURE}

\section{PARTICIPANTS}

From December 2018 to February 2019 a cross-sectional study was performed with a convenience sam- 
ple of women with breast cancer at the Breast Clinic of Iaso Hospital, which is one of the largest maternity hospitals in Athens (the capital city), Greece. The inclusion criteria were: (i) confirmed diagnosis of breast cancer under chemotherapy (for the group "during chemotherapy"), (ii) two years having passed since the last session of chemotherapy (for the group of "two years after chemotherapy), (iii) aged 18-65 years, (iv) having the ability of communication in Greek. Patients with psychiatric diseases or those who had been under surgery for breast cancer were excluded.

The researchers administered the questionnaires in the hospital setting. Participants undergoing chemotherapy completed the questionnaires inside the hospital and during chemotherapy with the presence of the researcher. Participants who had completed chemotherapy two years ago were found through clinical records of the Breast Clinic and they were called to the clinic to complete the questionnaires with the presence of the researcher.

From the 91 patients at the breast clinic, 80 were eligible (for both groups). Of these, 4 patients did not agree to participate in the study while 4 were excluded as they did not answer some items. Finally, 74 (for both groups) patients took part in the study. In order for both groups to be equivalent in terms of their characteristics, a stratification test was conducted based on demographic and clinical characteristics.

\section{MEASURES}

Participants were provided two scales which were personally administered to the participants alongside demographic information, such as age, gender, marital status, and educational level.

The Greek version of the Multidimensional Scale of Perceived Social Support (MSPSS; Theofilou, 2015). It is a self-reported scale which measures perceived social support across cultures. It was initially developed on university students (Zimet, Dahlem, Zimet, \& Farley, 1988). The MSPSS provides an assessment of three domains of perceived social support: Family (FA), Friends (FR), and Significant Others (SO). Each domain consists of 4 items. Each item is scored on a Likert-type scale ranging from 1 (very strongly disagree) to 7 (very strongly agree). Therefore, the total score ranges from 12 to 84 with higher scores indicating greater social support. The original version was constructed by Zimet et al. (1988) and has been translated into other languages (Aloba, Opakunle, \& Ogunrinu, 2019). The Greek version of MSPSS has good internal validity (Cronbach's $\alpha=.80$ ) (Theofilou, Zyga, Tzitzikos, Malindretos, \& Kotrotsiou, 2013) and has been used in elderly and haemodialysis patients (Lilympaki et al., 2016).

The Greek version of Missoula-VITAS Quality of Life Index (MVQoLI-15; Theofilou, Kapsalis, \& Panagio- taki, 2012). This scale measures the perceived QoL in the terminal stage of chronic illness. The MVQoLI-15 uses a five-point Likert-type scale (from strongly agree to strongly disagree) and collects information about 5 dimensions or domains of QoL: Symptoms, Function, Interpersonal, Well-being, and Transcendence. Every dimension includes three categories: Assessment (rating -2 to 2), Evaluation (rating -4 to 4 ), and Importance (rating 1 to 5). (Satisfaction + Assessment $) \times$ Importance $=$ QoL in each dimension. The total score ranges from 0 to 30 . The higher the score, the better the perceived QoL. The original version was constructed by Byock and Merriman (1998) and has been used in many hospital and health care settings (Adamopoulou et al., 2019; Dimova, Keskinova, Tzekov, \& Ginova-Noncheva, 2019). The scale has been translated (Theofilou et al., 2012) and validated in the Greek population by Theofilou, Aroni, Ralli, Gouzou, and Zyga (2013) with Cronbach's $\alpha=.74$.

Patients were also given a questionnaire with demographic characteristics.

\section{ETHICS}

The study was approved by the Ethics Committee of the Iaso Breast Clinic, at Iaso Hospital in Athens. Participants were informed about the aim of the study, the voluntary participation, the confidentiality of their answers and that the data would be used for research purposes only. Folders were provided to each participant and participants placed the questionnaires inside them in order to feel secure about the confidentiality of their answers. All patients signed an informed consent form.

\section{DATA ANALYSIS}

Qualitative variables were expressed as absolute $(N)$ and relative frequencies (\%) in each category of the variable and quantitative variables were expressed with mean, standard deviation, minimum and maximum values. All datasets were tested for normality using the Kolmogorov-Smirnov normality test (when the sample size was $n>30$ ) and the Shapiro-Wilk test (when the sample size was $n<30$ ). Depending on the distribution of a continuous variable in each cohort, either the $t$-test or the Mann-Whitney test was used to assess for differences. Analysis of variance (ANOVA) was used for investigating statistically significant differences between a quantitative variable and a qualitative variable with more than two categories, where the assumption of normality was met for all categories of the variable and the assumption of heterogeneity of variances was not violated (Leven's test). If there were statistically significant results, repeated measures were done with the least significant
Quality of life and social support in breast cancer 
difference method. In addition we examined with Pearson's correlation coefficient whether there was a statistically significant relationship between two quantitative variables which met the assumption of normality, while the non-parametric Spearman's coefficient correlation was examined if at least one of the quantitative variables did not meet the assumption of normality. All statistical tests were two-tailed, with significance set at $p<.05$. All statistical analyses were performed with SPSS 25.0 for Windows.

Iliana Goula,

Victoria Alikari, Georgios

Charalampous,

Foteini Tzavella, Sofia Zyga,

Maria Tsironi, Paraskevi Theofilou

\section{RESULTS}

The basic demographic characteristics are presented in Table 1 . The sample consisted of 74 women, $41(55.41 \%)$ of whom were "during chemotherapy" when this survey was conducted and the other $33(44.59 \%)$ were "two years after chemotherapy". In terms of age, participants were from 35 to 74 years old with a mean age of $52.79(S D=10.16)$ years.

The mean of the total MVQoLI-15 score was 19.00 $(S D=3.15)$ and of the total MSPSS score $5.24(S D=1.22)$ (Table 2).

Table 1
The results of statistical tests of differences in MVQoLI-15 and MSPSS between the two groups are presented in Table 3. There was a statistically significant difference in the median score of "total MVQoLI-15” ( $p=.044)$, “well-being” $(p=.007)$ and "transcendent" ( $p=.007)$ between the two groups while no statistically significant difference was observed in the median score of "total MSPSS" or any subscale score of MSPSS.

The results of the linear correlation between "total MVQoLI-15" and "total MSPSS" in each of the two groups are presented in Table 4. There was no statistically significant correlation between "total MVQoLI-15" and "total MSPSS" scores in each of the two groups ("during chemotherapy" period $p=.055$ and "two years after chemotherapy” $p=.141$ ).

A positive correlation was found between "total MSPSS" score and "age", for the "two years after chemotherapy" period ( $p=.037)$ and a negative correlation between "total MVQoLI-15" score and "age" for the "during chemotherapy" period $(p=.020)$ (Table 5).

There were no statistically significant differences in (a) scores of "total MVQoLI-15" given in each category for the variable "education" both in the "during

Characteristics of participants $(N=74)$

\begin{tabular}{|c|c|c|c|}
\hline & $\begin{array}{c}\text { During } \\
\text { chemotherapy } \\
n=41 \\
n(\%) \\
\end{array}$ & $\begin{array}{c}\text { Two years after } \\
\text { chemotherapy } \\
n=33 \\
n(\%)\end{array}$ & $\begin{array}{l}\text { Total } \\
N=74 \\
n(\%)\end{array}$ \\
\hline \multicolumn{4}{|l|}{ Age } \\
\hline$M$ & 49.97 & 55.94 & 52.79 \\
\hline$S D$ & 8.71 & 10.86 & 10.16 \\
\hline Min & 35 & 36 & 35 \\
\hline Max & 65 & 74 & 74 \\
\hline \multicolumn{4}{|l|}{ Marital status } \\
\hline Unmarried & $3(7.68 \%)$ & $5(15.57 \%)$ & $8(11.29 \%)$ \\
\hline Married & $33(84.58 \%)$ & $21(65.59 \%)$ & $54(76.09 \%)$ \\
\hline Divorced & $2(5.08 \%)$ & $3(9.40 \%)$ & $5(7.04 \%)$ \\
\hline Widow & $1(2.66 \%)$ & $3(9.40 \%)$ & $4(5.58 \%)$ \\
\hline \multicolumn{4}{|l|}{ Education } \\
\hline Secondary education & $17(45.93 \%)$ & $19(57.58 \%)$ & $36(51.38 \%)$ \\
\hline Technological institute & $11(29.73 \%)$ & $8(24.17 \%)$ & $19(27.18 \%)$ \\
\hline University graduate high level & $9(24.33 \%)$ & $6(18.18 \%)$ & $15(21.41 \%)$ \\
\hline \multicolumn{4}{|l|}{ Working status } \\
\hline Employee & $23(60.48 \%)$ & $15(45.49 \%)$ & $38(53.51 \%)$ \\
\hline Not employee & $15(39.47 \%)$ & $18(54.48 \%)$ & $33(46.48 \%)$ \\
\hline
\end{tabular}


Table 2

Descriptive statistics of MVQoLI-15 and MSPSS

\begin{tabular}{|c|c|c|c|c|}
\hline & $M$ & $S D$ & Min & Max \\
\hline \multicolumn{5}{|l|}{ MVQoLI-15 } \\
\hline Global score & 3.90 & 0.70 & 2.00 & 5.00 \\
\hline $\begin{array}{l}\text { Symptoms } \\
\text { Theoretical range: }(-30)-(+30)\end{array}$ & 6.39 & 5.02 & -9.00 & 16.00 \\
\hline $\begin{array}{l}\text { Function } \\
\text { Theoretical range: }(-30)-(+30)\end{array}$ & 4.77 & 10.61 & -20.00 & 25.00 \\
\hline $\begin{array}{l}\text { Interpersonal } \\
\text { Theoretical range: }(-30)-(+30)\end{array}$ & 13.15 & 11.99 & 35.00 & 30.00 \\
\hline $\begin{array}{l}\text { Well-being } \\
\text { Theoretical range: }(-30)-(+30)\end{array}$ & 0.41 & 12.68 & 74.00 & 30.00 \\
\hline $\begin{array}{l}\text { Transcendent } \\
\text { Theoretical range: }(-30)-(+30)\end{array}$ & 14.95 & 12.23 & 74.00 & 30.00 \\
\hline Total score & 19.00 & 3.15 & 11.00 & 25.30 \\
\hline \multicolumn{5}{|l|}{ MSPSS } \\
\hline $\begin{array}{l}\text { Significant other } \\
\text { Theoretical range: } 4-28\end{array}$ & 5.62 & 5.88 & 2.75 & 7.00 \\
\hline $\begin{array}{l}\text { Family } \\
\text { Theoretical range: } 4-28\end{array}$ & 5.33 & 1.48 & 1.75 & 7.00 \\
\hline $\begin{array}{l}\text { Friends } \\
\text { Theoretical range: } 4-28\end{array}$ & 4.78 & 1.54 & 1.00 & 7.00 \\
\hline $\begin{array}{l}\text { Total score } \\
\text { Theoretical range: } 12-84\end{array}$ & 5.24 & 1.22 & 3.00 & 7.00 \\
\hline
\end{tabular}

Quality of life and social support in breast cancer chemotherapy" period (one-way analysis of variance, $F=1.12, p=.340$ ), "two years after chemotherapy" period (one-way analysis of variance, $F=0.54, p=.589$ ) and in the total sample (b) between "total MVQoLI-15" given in each category for the variable "marital status" (one-way analysis of variance, $F=1.72, p=.174$ ) for both periods and in the total sample, (c) between the median score of "total MVQoLI-15" between "employee" and "not employee" (Mann-Whitney $U$ test $=360.50, p=.142$ ) for both periods, (d) between "total MSPSS" given in each category for the variable "Education" $(p>.05)$ for all the cases (in total, during chemotherapy, two years after chemotherapy) (Kruskal-Wallis $H=.25, p=.882$ ).

There was a statistically significant difference in the median score of "total MSPSS" between "employee" and "not employee" (Mann-Whitney $U$ test $=346.50$, $p=.028)$. More specifically, "not employee" had a greater median "total MSPSS" score (median = 5.96, mean rank $=37.95)$ than "employee" $($ median $=4.60$, mean rank $=27.69$ ). There were statistically significant differences in scores of "total MSPSS" given in each category for the variable "marital status" (one-way analysis of variance, $F=3.09, p=.046$ ) for the period "two years after chemotherapy". The category "unmarried" had a lower "total MSPSS" score (4.10 \pm 1.26$)$ than the category "divorced" $(6.38 \pm 6.75, p=.019)$ and "widow" (6.44 $\pm 6.58, p=.016)$. For the period "during chemotherapy", there was no statistically significant difference in mean scores of "total MSPSS" between the two groups of "marital status" ("unmarried" $M=4.89, S D=0.75, t=-0.19, d f=31, p=.852$, "married" $M=5.02, S D=1.17$ ).

\section{DISCUSSION}

The present study aimed to investigate the differences in the levels of quality of life and social support during and two years after chemotherapy.

One of the main results of the present study is that there was a statistically significant difference in the quality of life for women who were currently undergoing chemotherapy in comparison to those who had completed the chemotherapy process two years ago. More specifically, the women who had completed the chemotherapy two years ago reported that they had better QoL than those who belonged 
Table 3

Differences in MVQoLI-15 and MSPSS scores between the two groups

Iliana Goula,

Victoria Alikari, Georgios

Charalampous,

Foteini Tzavella, Sofia Zyga, Maria Tsironi, Paraskevi Theofilou

\begin{tabular}{|c|c|c|c|c|c|c|}
\hline & & Mean & Median & $\begin{array}{c}\text { Mean } \\
\text { rank }\end{array}$ & $\begin{array}{c}\text { Mann- } \\
\text { Whitney } U^{*}\end{array}$ & $\begin{array}{c}\text { Overall } \\
p\end{array}$ \\
\hline \multicolumn{7}{|l|}{ MVQoLI-15 } \\
\hline \multirow{2}{*}{$\begin{array}{l}\text { Total } \\
\text { MVQoLI-15 }\end{array}$} & During chemotherapy & 18.37 & 18.00 & 28.09 & 336.50 & .044 \\
\hline & Two years after chemotherapy & 19.90 & 19.60 & 37.56 & & \\
\hline \multirow[t]{2}{*}{ Symptoms } & During chemotherapy & 5.56 & 6.00 & 32.46 & 485.50 & .226 \\
\hline & Two years after chemotherapy & 7.47 & 7.00 & 38.32 & & \\
\hline \multirow[t]{2}{*}{ Interpersonal } & During chemotherapy & 13.26 & 15.00 & 32.71 & 502.00 & .696 \\
\hline & Two years after chemotherapy & 13.00 & 16.00 & 34.57 & & \\
\hline \multirow[t]{2}{*}{ Well-being } & During chemotherapy & -3.20 & -4.50 & 30.18 & 387.00 & .007 \\
\hline & Two years after chemotherapy & 5.06 & 8.00 & 43.52 & & \\
\hline \multirow[t]{2}{*}{ Transcendent } & During chemotherapy & 11.82 & 12.00 & 30.19 & 387.50 & .007 \\
\hline & Two years after chemotherapy & 19.00 & 20.00 & 43.50 & & \\
\hline \multirow[t]{2}{*}{ Function $(S D)$} & During chemotherapy & $5.39(10.23)$ & \multirow{2}{*}{\multicolumn{3}{|c|}{$t=0.54, d f=66^{* *}$}} & .594 \\
\hline & Two years after chemotherapy & $4.00(11.19)$ & & & & \\
\hline \multicolumn{7}{|l|}{ MSPSS } \\
\hline \multirow[t]{2}{*}{ Total MSPSS } & During chemotherapy & 5.14 & 5.00 & 32.08 & 484.00 & .497 \\
\hline & Two years after chemotherapy & 5.38 & 5.75 & 35.31 & & \\
\hline \multirow{2}{*}{$\begin{array}{l}\text { Significant } \\
\text { other }\end{array}$} & During chemotherapy & 5.55 & 6.00 & 34.18 & 561.50 & .881 \\
\hline & Two years after chemotherapy & 5.67 & 5.75 & 34.89 & & \\
\hline \multirow[t]{2}{*}{ Family } & During chemotherapy & 5.25 & 5.12 & 33.75 & 541.50 & .562 \\
\hline & Two years after chemotherapy & 5.42 & 6.00 & 36.53 & & \\
\hline \multirow[t]{2}{*}{ Friends } & During chemotherapy & 4.57 & 4.38 & 32.78 & 504.50 & .306 \\
\hline & Two years after chemotherapy & 5.04 & 4.75 & 37.73 & & \\
\hline
\end{tabular}

Note. ${ }^{*}$ Nonparametric Mann-Whitney $U$ test (for dimensions which did not meet the assumption of normality), * Student's $t$-test only for the dimension "function" which met the assumption of normality for both categories of the variable.

Table 4

Spearman correlation between total MVQoLI-15 and total MSPSS scores by period

\begin{tabular}{lcccc}
\hline & During chemotherapy & \multicolumn{2}{c}{ Two years after chemotherapy } \\
\hline & & Total MVQoLI-15 score \\
& Spearman correlation $(r)$ & $p$ & Spearman correlation $(r)$ & $p$ \\
Total MSPSS score & .33 & .056 & .30 & .141 \\
\hline
\end{tabular}

to the chemotherapy group. This result is consistent with the results of previous studies as they indicated that the process of chemotherapy constitutes a very distressing period in women's lives and is associated with a low quality of life (Arora et al., 2007; Kameo \& Sawada, 2016; Coelho et al., 2018). Some studies report that women who are currently undergoing chemotherapy are more likely to develop feelings of depression, unmet sexual needs, feelings of uncertainty about their future health and concerns about their physical and emotional well-being compared to women who are not in chemotherapy (Hwang, Chang, \& Park, 2013; Tiezzi et al., 2017). This result also indicates that although the period following the end of chemotherapy is accompanied by psychosocial distress (Grassi, Spiegel, \& Riba, 2017), these 


\begin{tabular}{|c|c|c|c|c|c|c|}
\hline & \multicolumn{2}{|l|}{ During chemotherapy } & \multicolumn{2}{|l|}{$\begin{array}{l}\text { Two years after } \\
\text { chemotherapy }\end{array}$} & \multicolumn{2}{|l|}{ Total } \\
\hline & & & Total MVQoLI-15 sco & & & \\
\hline & Spearman correlation $(r)$ & $p$ & Spearman correlation $(r)$ & $p$ & Spearman correlation $(r)$ & $p$ \\
\hline \multirow[t]{3}{*}{ Age } & -.39 & .020 & -.07 & .722 & -.17 & .192 \\
\hline & & & Total MSPSS score & & & \\
\hline & Pearson correlation $(r)$ & $p$ & Pearson correlation $(r)$ & $p$ & Pearson correlation $(r)$ & $p$ \\
\hline Age & .25 & .153 & .39 & .037 & .08 & .529 \\
\hline
\end{tabular}

Quality of life and social support in breast cancer women eventually manage to get a positive message on this painful experience of chemotherapy.

In this study, there was no difference in perceived social support between the two patient groups. Both of the two groups reported that they received a high degree of support from their immediate environment (family, friends, and important others). Given the fact that in the present study women who had completed chemotherapy two years ago reported a higher QoL than those undergoing chemotherapy, they may have been particularly helped by the social support they received from their environment. Dumrongpanapakorn and Liamputtong (2017) reported that women with breast cancer receive a lot of support from their environment. Rizalar, Ozbas, Akyolcu, and Gungor (2014) found that social support played a crucial role in restoring the lifestyle of women after chemotherapy. Another result of the present study is that the level of education does not correlate with the level of patients' quality of life. This result is inconsistent with previous studies according to which the higher the educational level of women with breast cancer, the better the level of QoL they experience. Timperi et al. (2013) found that women with breast cancer had better QoL than patients who had a low educational level while others highlight that the high educational level helps them to have better access to information, a better set of tools and disease management strategies (Villar et al., 2017). Regarding the role of educational level in the perceived social support of women patients regardless of the group they belong to, we found no statistically significant differences between the two groups. The studies indicate that the level of education plays a significant role in the way in which each patient with breast cancer receives social support from her environment. More specifically, it has been found that people with a high level of education develop very emotional relationships and accept support from their environment more easily (Ozdemir \& Tas Arslan, 2018).

Age, on the other hand, seems to be a factor that plays a crucial role in the patients' quality of life, according to the results of the present study. Especially for women who are in chemotherapy, age is important for them in the way they manage this whole painful process. More specifically, it appears that the higher the patient's age, the lower their quality of life. Although the influence of age in this study agrees with all the studies already conducted, it is inconsistent on the other hand with the type of correlation between age and quality of life. The majority of studies that have been conducted suggest that patients with a lower age are more negatively affected by chemotherapy compared to older women and thus they report lower quality of life (Engel et al., 2003; Sammarco, 2009). As for social support, this study found that older women with breast cancer who completed chemotherapy two years ago receive more social support in comparison to the younger women. In contrast, there were no differences in the group of women undergoing chemotherapy. The present result can be explained, however, since it has been found that adulthood is a period of increasing social functioning (Pettit, Roberts, Lewinsohn, Seeley, \& Yaroslavsky, 2011). So, as an adult woman grows up, she chooses more consciously the people she wants to have next to her (Pettit et al., 2011).

Another result of the present study is that marital status does not correlate with patients' quality of life either during chemotherapy or two years after the end of chemotherapy. This result seems to be inconsistent with previous studies as the majority of them indicate that unmarried women have a lower quality of life in comparison to married women (Martínez et al., 2017).

Another result of the present study was that marital status plays a significant role in the magnitude of perceived social support especially for women who completed chemotherapy two years ago. More specifically, the women who were unmarried seemed to accept less social support in comparison to those who were divorced. The specific result is consistent with those of the previous studies, which in their vast majority have concluded that unmarried women, who have breast cancer, report lower social support than the others (Salim, Borhani, Pour, 
Iliana Goula,

Victoria Alikari,

Georgios

Charalampous,

Foteini Tzavella, Sofia Zyga,

Maria Tsironi, Paraskevi Theofilou
\& Khabazkhoob, 2019; Thompson, Rodebaugh, Perez, Schootman, \& Jeffe, 2013). The reasons why patients who are single, separated or widowed report a low level of perceived social support is that these patients may experience feelings of loneliness and isolation even if the rest of their environment is particularly supportive towards them (Salim et al., 2019). On the other hand, the present study indicated that there was no difference in the perceived social support for the women who were under chemotherapy. This result may be explained by the fact that women during chemotherapy have a particular need to be supported by doctors and nurses and perhaps the support of the husband may come second (Salim et al., 2019).

Another result of the present study is that the working status of women with breast cancer plays a role in perceived social support. More specifically, it was found that unemployed women reported greater perceived social support than those who were employed. A possible explanation for this result is that perhaps women who work are not so much based on social support they receive from their environment since the occupation is a way of relieving their feelings. Additionally, employment usually gives a sense of power and independence to women, as well as a sense of ability to manage a difficult situation. This helps them stand more easily on their feet than unemployed women.

The small number of participants could be considered the first limitation of this study. Therefore, studies with a larger sample from more hospitals in the broad area of Greece should be conducted in order to generalize the results. In addition, the fatigue of patients, the noise of the environment and the presence of others should be considered as the study was carried out in the place of the hospital. Moreover, future studies should include women who have undergone mastectomy or breast reconstruction for comparison with these subgroups.

\section{CONCLUSIONS}

According to the findings of the current study, women who completed the chemotherapy two years ago experience better QoL than those who are currently under chemotherapy. Older women of the "during chemotherapy" group reported lower QoL while older women of the "two years after chemotherapy" group experienced more social support than younger ones. As far as social support is concerned, it seems that there is no difference between the two groups but it plays a crucial role in both groups.

\section{ACKNOWLEDGMENTS}

We thank patients for their participation and the Scientific Council of Iaso Hospital.

\section{REFERENCES}

Adamopoulou, F., Alikari, V., Zyga, S., Tsironi, M., Tzavella, F., Giannakopoulou, N., \& Theofilou, P. (2019). The effect of fatigue and pain self-efficacy on health-related quality of life among patients with multiple sclerosis. Materia Socio-medica, 31, 40-44. https://doi.org/10.5455/msm.2019.31.40-44

Akechi, T., Uchida, M., Nakaguchi, T., Okuyama, T., Sakamoto, N., Toyama, T., \& Yamashita, H. (2015). Difference of patient's perceived need in breast cancer patients after diagnosis. Japanese Journal of Clinical Oncology, 45, 75-80. https://doi. org/10.1093/jjco/hyu 165

Aloba, O., Opakunle, T., \& Ogunrinu, O. (2019). Psychometric characteristics and measurement invariance across genders of the Multidimensional Scale of Perceived Social Support (MSPSS) among Nigerian adolescents. Health Psychology Report, 7, 69-80. https://doi.org/10.5114/hpr.2019.82629

Arora, N. K., Rutten, L. J. F., Gustafson, D. H., Moser, R., \& Hawkins, R. P. (2007). Perceived helpfulness and impact of social support provided by family, friends, and health care providers to women newly diagnosed with breast cancer. Psycho-Oncology, 16, 474-486. https://doi.org/10.1002/pon.1084

Bloom, J. R., Stewart, S. L., Johnston, M., Banks, P. \& Fobair, P. (2001). Sources of social Support and the physical and mental well-being of young women with breast cancer. Social Science \& Medicine, 53, 1513-1524. https://doi.org/10.1016/S02779536(00)00440-8

Bloom, J. R., Stewart, S. L., Chang, S., \& Banks, P. J. (2004). Then and now: Quality of life of young breast cancer survivors. Psycho-Oncology, 13, 147160. https://doi.org/10.1002/pon.794

Burgess, C., Cornelius, V., Love, S., Graham, J., Richards, M., \& Ramirez, A. (2005). Depression and anxiety in women with early breast cancer: Five year observational cohort study. British Medical Journal, 330, 702-705. https://doi.org/10.1136/ bmj.38343.670868.D3

Byock, I. R., \& Merriman, M. P. (1998). Measuring quality of life for patients with terminal illness: the Missoula-VITAS quality of life index. Palliative Medicine, 12, 231-244. https://doi. org/10.1191/026921698670234618

Coelho, R. C. F. P., Nunes Garcia, S., Marcondes, L., da Silva, F. A. J., de Paula, A., \& Puchalski Kalinke, L. (2018). Impact on the quality of life of women with breast cancer undergoing chemotherapy in public and private care. Investigación y Educación en Enfermería, 36, e4. https://doi. org/10.17533/udea.iee.v36n1e04

Dimova, R., Keskinova, D., Tzekov, V., \& GinovaNoncheva, G. (2019). Health-related quality of life in end-stage renal disease patients, using the Missoula-Vitas quality of life index: a multicenter 
study. Medicine and Pharmacy Reports, 92, 374381. https://doi.org/10.15386/mpr-1320

Dumrongpanapakorn, P., \& Liamputtong, P. (2017). Social support and coping means: The lived experiences of Northeastern Thai women with breast cancer. Health Promotion International, 32, 768777. https://doi.org/10.1093/heapro/dav023

Engel, J., Kerr, J., Schlesinger-Raab, A., Eckel, R., Sauer, H., \& Hölzel, D. (2003). Predictors of quality of life of breast cancer patients. Acta Oncologica, 42, 710718. https://doi.org/10.1080/02841860310017658

Fradelos, E. C., Papathanasiou, I. V., Veneti, A., Daglas, A., Christodoulou, E., Zyga, S., \& Kourakos, M. (2017). Psychological distress and resilience in women diagnosed with breast cancer in Greece. Asian Pacific Journal of Cancer Prevention, 18, 25452550. https://doi.org/10.22034/APJCP.2017.18.9.2545

Gibek, K., \& Sacha, T. (2019). Comparison of health locus of control in oncological and non-oncological patients. Contemporary Oncology, 23, 115-120. https://doi.org/10.5114/wo.2019.85638

Grassi, L., Spiegel, D., \& Riba, M. (2017). Advancing psychosocial care in cancer patients. F1000Research, 6, 2083. https://doi.org/10.12688/f1000research.11902.1

Hwang, S. Y., Chang, S. J., \& Park, B. W. (2013). Does chemotherapy really affect the quality of life of women with breast cancer? Journal of Breast Cancer, 16, 229-235. https://doi.org/10.4048/jbc.2013.16.2.229

Kameo, S. Y. \& Sawada, N. O. (2016). Quality of life and adverse reactions caused by chemotherapy in breast cancer: an integrative review. IOSR Journal of Pharmacy, 6, 51-61.

Kırca, K., \& Kutlutürkan, S. (2018). Symptoms experience and quality of life in the patients with breast cancer receiving the taxane class of drugs. European Journal of Breast Health, 14, 148-155. https:// doi.org/10.5152/ejbh.2018.3785

Lavdaniti, M., Owens, D. A., Liamopoulou, P., Marmara, K., Zioga, E., Mantzanas, M. S., Evangelidou, E. \& Vlachou, E. (2019). Factors influencing quality of life in breast cancer patients six months after the completion of chemotherapy. Diseases, 7, e26. https://doi.org/10.3390/diseases7010026

Lilympaki, I., Makri, A., Vlantousi, K., Koutelekos, I., Babatsikou, F., \& Polikandrioti, M. (2016). Effect of perceived social support on the levels of anxiety and depression of hemodialysis patients. Materia Sociomedica, 28, 361-365. https://doi.org/10.5455/ msm.2016.28.361-365

Martínez, M. E., Unkart, J. T., Tao, L., Kroenke, C. H., Schwab, R., Komenaka, I., \& Gomez, S. L. (2017). Prognostic significance of marital status in breast cancer survival: a population-based study. PLoS One, 12, e0175515. https://doi.org/10.1371/journal. pone. 0175515

Ozdemir, D., \& Tas Arslan, F. (2018). An investigation of the relationship between social support and coping with stress in women with breast cancer.
Psycho-Oncology, 27, 2214-2219. https://doi.org/ 10.1002/pon.4798

Pettit, J. W., Roberts, R. E., Lewinsohn, P. M., Seeley, J. R., \& Yaroslavsky, I. (2011). Developmental relations between perceived social support and depressive symptoms through emerging adulthood: blood is thicker than water. Journal of Family Psychology, 25, 127-136. https://doi.org/10.1037/ a0022320

Rivera, E., \& Cianfrocca, M. (2015). Overview of neuropathy associated with taxanes for the treatment of metastatic breast cancer. Cancer Chemotherapy and Pharmacology, 75, 659-670. https://doi. org/10.1007/s00280-014-2607-5

Rizalar, S., Ozbas, A., Akyolcu, N., \& Gungor, B. (2014). Effect of perceived social support on psychosocial adjustment of Turkish patients with breast cancer. Asian Pacific Journal of Cancer Prevention, 15, 34293434. https://doi.org/10.7314/apjcp.2014.15.8.3429

Rustøen, T., \& Schjølberg, T. K. (2000). Cancer nursing research priorities: a Norwegian perspective. Cancer Nursing, 23, 375-381. https://doi.org/10.1097/ 00002820-200010000-00009

Salim, N. F., Borhani, F., Pour, M. B., \& Khabazkhoob, M. (2019). Correlation between perceived social support and resilience in the family of patients with cancer. Journal of Research in Medical and Dental Science, 7, 158-162.

Salonen, P., Tarkka, M. T., Kellokumpu-Lehtinen, P. L., Koivisto, A. M., Aalto, P., \& Kaunonen, M. (2013). Effect of social support on changes in quality of life in early breast cancer patients: a longitudinal study. Scandinavian Journal of Caring Sciences, 27, 396-405. https://doi.org/10.1111/j.14716712.2012.01050.x

Sammarco, A. (2009). Quality of life of breast cancer survivors: a comparative study of age cohorts. Cancer Nursing, 32, 347-358. https://doi.org/10.1097/ NCC.0b013e31819e23b7

Sharma, N., \& Purkayastha, A. (2017). Factors affecting quality of life in breast cancer patients: a descriptive and cross-sectional study with review of literature. Journal of Mid-Life Health, 8, 75-83. https://doi.org/10.4103/jmh.JMH_15_17

Theofilou, P. (2015). Translation and cultural adaptation of the Multidimensional Scale of Perceived Social Support for Greece. Health Psychology Research, 3, 1061. https://doi.org/10.4081/hpr.2015.1061

Theofilou, P., Aroni, A., Ralli, M., Gouzou, M., \& Zyga, S. (2013). Measuring health: Related quality of life in hemodialysis patients. Psychometric properties of the Missoula-VITAS Quality of Life Index (MVQoLI-15) in Greece. Health Psychology Research, 1, e17. https://doi.org/10.4081/hpr.2013.e17

Theofilou, P., Kapsalis, F., \& Panagiotaki, H. (2012). Greek version of MVQoLI-15: Translation and cultural adaptation. International Journal of Caring Sciences, 5, 289-294.
Quality of life and social support in breast cancer 
Theofilou, P., Zyga, S., Tzitzikos, G., Malindretos, P., \& Kotrotsiou, E. (2013). Assessing social support in Greek patients on maintenance hemodialysis: Psychometric properties of the Multi-Dimensional Scale of Perceived Social Support. In E. AbdelRahman, R. A. Balogun, \& S. A. Balogun (Eds.), Chronic kidney disease: Signs/symptoms, management options and potential complications (pp. 265279). Hauppauge, NY: Nova Science Publishers.

Thompson, T., Rodebaugh, T. L., Pérez, M., Schoot-

Iliana Goula, Victoria Alikari, Georgios Charalampous, Foteini Tzavella, Sofia Zyga, Maria Tsironi, Paraskevi Theofilou man, M., \& Jeffe, D. B. (2013). Perceived social support change in patients with early stage breast cancer and controls. Health Psychology, 32, 886895. https://doi.org/10.1037/a0031894

Tiezzi, M. F., de Andrade, J. M., Romão, A. P., Tiezzi, D. G., Lerri, M. R., Carrara, H. A., \& Lara, L. A. (2017). Quality of life in women with breast cancer treated with or without chemotherapy. Cancer Nursing, 40, 108-116. https://doi.org/10.1097/ NCC.0000000000000370

Timperi, A. W., Ergas, I. J., Rehkopf, D. H., Roh, J. M., Kwan, M. L., \& Kushi, L. H. (2013). Employment status and quality of life in recently diagnosed breast cancer survivors. Psycho-Oncology, 22, 1411-1420. https://doi.org/10.1002/pon.3157

Turgay, A. S., Khorshid, L., \& Eser, I. (2008). Effect of the first chemotherapy course on the quality of life of cancer patients in Turkey. Cancer Nursing, 31, 9-23. https://doi.org/10.1097/01.NCC.0000339248. 37829.c2

Villar, R. R., Fernández, S. P., Garea, C. C., Pillado, M., Barreiro, V. B., \& Martín, C. G. (2017). Quality of life and anxiety in women with breast cancer before and after treatment. Revista Latino-Americana de Enfermagem, 25, e2958. https://doi.org/10.1590/15188345.2258.2958

Wyatt, G., Beckrow, K. C., Gardiner, J., \& Pathak, D. (2008). Predictors of postsurgical subacute emotional and physical well-being among women with breast cancer. Cancer Nursing, 31, E28-E39. https:// doi.org/10.1097/01.NCC.0000305705.91787.55

Zimet, D. G., Dahlem, N. W., Zimet, S. G., \& Farley, G. K. (1988). The Multidimensional Scale of Perceived Social Support. Journal of Personality Assessment, 52, 30-41. https://doi.org/10.1207/s15327752jpa5201_2 